\title{
Envelhecer a Dançar: Matinés Dançantes
}

\author{
Ana Nunes*, Paula Batista*, Catarina Henriques*, Catarina Calado*, Alcino Silva**, Henrique Mendes-dos-Santos*** \\ * Obra de Promoção Social do Distrito de Coimbra / CLDS+ Coimbra Concelho Solidário e Saudável, **Câmara Municipal de \\ Coimbra - Divisão de Educação e Ação Social/ CLDS+ Coimbra Concelho Solidário e Saudável, ***Obra de Promoção Social do \\ Distrito de Coimbra
}

\begin{abstract}
Resumo
O aumento da esperança média de vida tem-nos reconduzido, paulatinamente, à inevitável criação e desenvolvimento de estratégias votadas à autonomía e bem-estar dos idosos. Exemplo do que acaba de se expor são as ações de convívio, que têm sido apontadas como estratégias que favorecem o envelhecimento ativo. A socialização promove a comunicação e facilita a partilha de saberes e experiências de vida. Ademais, devidamente adaptadas às características da população idosa, nomeadamente, através da dança, podemos estimular e beneficiar as capacidades físicas e mentais, permitindo quebrar preconceitos, aumentando a capacidade comunicativa e a autoestima. Permite ainda resgatar lembranças da juventude, muitas vezes marcada por festas populares e religiosas, os vulgares "bailaricos", que constituíam fonte de confraternização.

Palavras chave: envelhecimento ativo, qualidade de vida, bem-estar, dança, aprendizagem ao longo da vida.
\end{abstract}

\section{Introdução}

Um envelhecimento ativo e com qualidade constitui um desafio social atual, que pode repercutir-se positivamente ao nível regional, pela vivência da comunidade local, mas também, e por conseguinte, ao nível nacional, levando ao desenvolvimento do país sob os mais variados aspectos.

Com a esperança média de vida a aumentar é fundamental encontrar respostas sociais que contribuam para um envelhecimento saudável, respostas essas pelas quais se combata o abandono, a exclusão e o isolamento social. Para que a população envelhecida desfrute, na sua plenitude, de uma velhice com qualidade, é necessário promover momentos de lazer, convívio e aprendizagem ao longo da vida. Dever-se-á ainda diligenciar esforços junto da população sénior para que pratiquem atividade física, informando-os dos benefícios. Para além dos benefícios para a saúde, possibilitam a confraternização, a partilha de experiências e contribuem para a satisfação e bem-estar.

O programa dos Contratos Locais de Desenvolvimento Social Mais (CLDS+) surge aqui como uma resposta social válida, com um plano de ação alicerçado em três eixos: Eixo 1 - Emprego, Formação e Qualificação; Eixo 2 - Intervenção Familiar e Parental Preventiva da Pobreza Infantil; e, Eixo 3 - Capacitação da Comunidade e das Instituições.

O CLDS+ Coimbra Concelho Solidário e Saudável conta com a Obra de Promoção Social do Distrito de Coimbra (OPSDC) como entidade coordenadora e com a
Câmara Municipal de Coimbra como entidade promotora. Teve o seu período de execução de Março de 2014 a Junho de 2015.

Uma das principais ações precunizadas foram as chamadas Matinés Dançantes, destinadas à população idosa das dezoito Uniões/Juntas de Freguesias do Concelho de Coimbra e visaram, fundamentalmente, proporcionar momentos de lazer e convívio à população sénior, bem como o combate ao isolamento e exclusão social.

As várias instituições foram convidadas a participar com momentos musicais e/ou teatrais, nos quais brilharam as grandes vedetas, os idosos. No final, realizava-se um lanche partilhado, confecionado pelas instituições participantes e/ou patrocinado pelo comércio local, o que possibilitou combater conceitos negativos como a solidão, o isolamento e a falta de autonomia, antes se promovendo a felicidade, o convívio, a autoestima e o bem-estar dos participantes. Num tal contexto foi ainda possível alertar para a responsabilidade social das instituições e da comunidade em geral.

\section{Missão}

Com as Matinés Dançantes pretendeu-se salientar o contributo da dança no processo de envelhecimento ativo e com qualidade. Destacou-se, por essa via, o contributo social das mesmas e apelou-se à importância da criação de uma cultura de envelhecimento ativo, baseada numa sociedade para todas as idades.

Os "Bailaricos", enquanto ações de carater sociocultural, dirigidas à população sénior das freguesias do concelho de Coimbra, permitiu ainda:

1. Promover momentos de convívio e partilha;

2. Combater o isolamento e exclusão social;

3. Estabelecer uma relação de proximidade entre IPSS, idosos e a comunidade;

4. Promover a participação ativa e saudável;

5. Melhorar a autoestima e a satisfação dos idosos;

6. Combater o sedentarismo.

\section{Metodologia}

O presente trabalho assenta no paradigma qualitativo, dando-se primazia à observação naturalista e avaliação da narrativa. Por forma a complementá-lo, é utilizado o registo fotográfico, que permite retratar as Matinés Dançantes de forma fiel e fidedigna.

\section{Financiamento dos Programas CLDS+: POPH e Jogos Sociais}

Correspondencia: Ana Nunes, anaraqnunes@gmail.com, Paula Batista, paulaifbatista@live.com.pt, Catarina Henriques, cati_henriques26@hotmail.com, Catarina Calado, a.catarinacalado@gmail.com, Alcino Silva, silva.alcino@gmail.com, Henrique Mendes dos Santos, presidente@opsdc.pt 


\section{Resultados}

Foram realizadas Matinés Dançantes nas 18 Uniões/Freguesias do Concelho de Coimbra.

Através das Comissões Sociais de Freguesia (CSF) foram contactadas/convidadas as IPSS e Associações que trabalham com a população sénior (e.g., Lares da Terceira Idade e Centros de Dia com as mais diversas valências). A população local foi também convidada a participar.

A primeira Matiné Dançante decorreu na UF de São Martinho do Bispo e Ribeira de Frades (UFSMBRF), no dia 22 de Outubro de 2014 (vide Figura 1.) com a presença de 86 idosos provenientes de instituições da União de Freguesias.

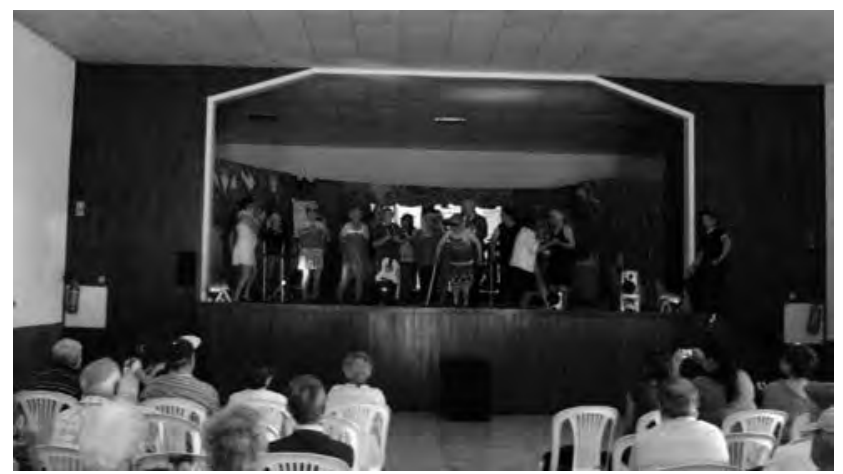

Figura 1. Matiné dançante na UFSMBRF

Após a realização das 18 matinés, foi contabilizado o número total de participantes, o que prefez 464 idosos. Através de uma análise detalhada constatou-se que o género feminino teve uma participação mais representativa (vide Figura 2.)

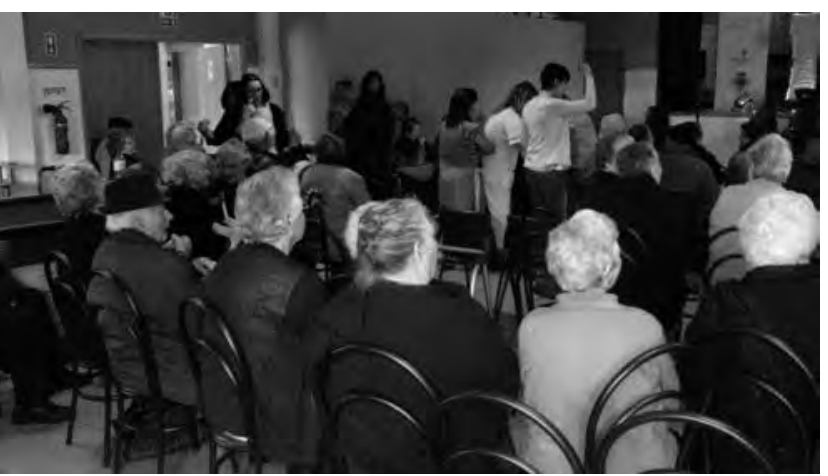

Figura 2. Maior representatividade do género feminino Matiné dançante UF Eiras e São Paulo de Frades

Verificamos ainda que algumas IPSS, a convite das CSF, participaram uma segunda vez.

Foi ainda realizada uma Matiné de Reis, no dia 6 de Janeiro de 2015, que teve lugar no Pavilhão Centro de Portugal, no Parque Verde do Mondego, em Coimbra (vide Figura 3.), onde participaram 15 instituições do concelho. No final, foi distribuido o bolo próprio da época (Bolo Rei).

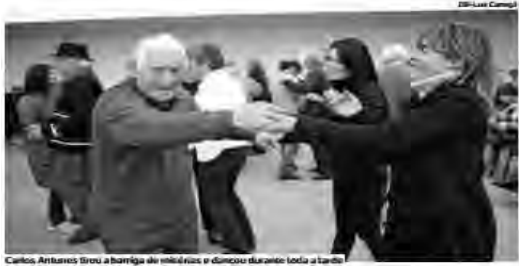

\section{A matiné onde os idosos} foram "Reis" da festa

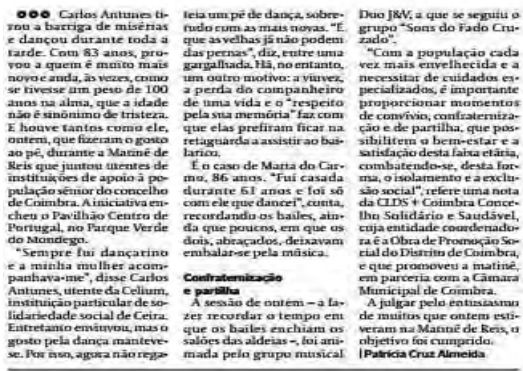

Figura 3. Notícia de Jornal - Matiné de Reis

Face às considerações acima expendidas concluimos que as Matinés dançantes tiveram uma grande adesão e possibilitaram o contacto intergeracional (vide Figuras 4. e 5.).

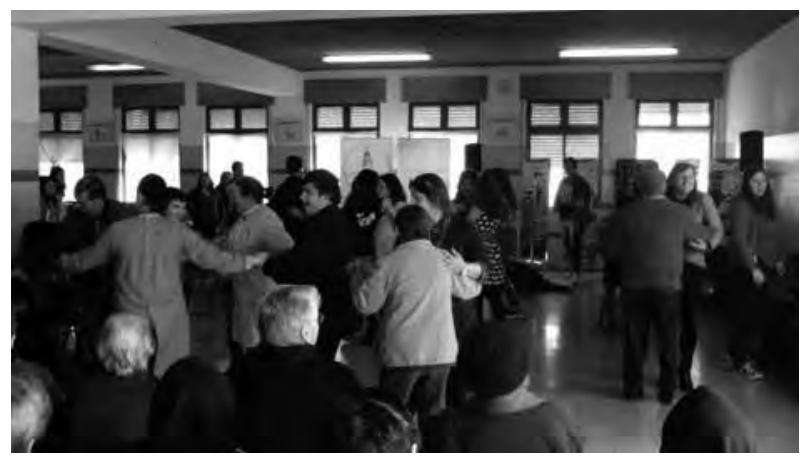

Figura 4. Matiné Dançante da Freguesia de S. Silvestre

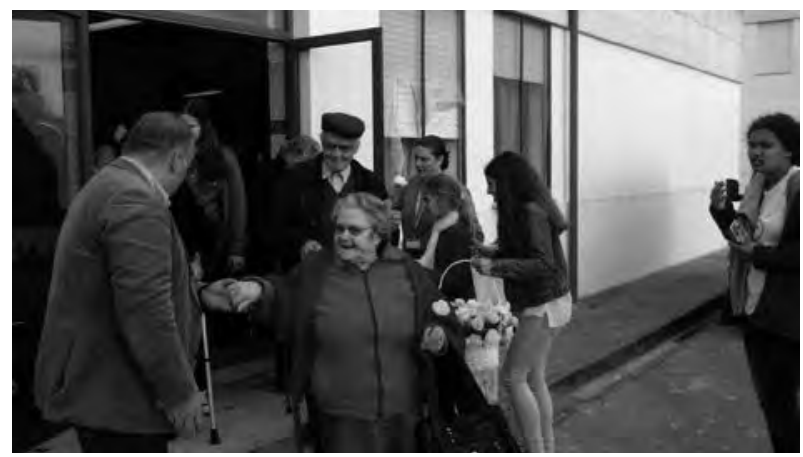

Figura 5. Regresso a Casa - Matiné Dançante da Freguesia de S. Silvestre 
Os comentários tecidos pelos participates - idosos, diretores técnicos e elementos da comunidade - foram muito positivos. $\mathrm{Na}$ generalidade, consideraram pertinente dar-se continuidade a estas atividades.

\section{Conclusão}

A dança é por muitos autores defendida e descrita como promotora de bem-estar e "ferramenta" que estimula as capacidades cognitivas e psicomotoras, independentemente da idade ou género. Em especial, no período da velhice, a dança permite manter o corpo ativo, a mente sã, o convívio, a partilha de experiências e desperta o sentimento de bem-estar. Para além disso, através de atividades lúdicas e recreativas, combate o isolamento social e o sedentarismo, e possibilita a confraternização entre vizinhos e elementos da comunidade, o que facilita a aproximação e a comunicação entre pares. De acordo com Mortari (2013), a dança "constitui uma manifestação artística com forte significado social que, por ser uma forma de comunicação, une o corpo e o ambiente que o rodeia com uma linguagem comum”. Exemplo disto, são as matinés dançantes, que inseriram algum dinamismo nas freguesias/uniões de freguesia do concelho de Coimbra, proporcionaram o estabelecimento de uma maior proximidade com a comunidade, nomeadamente, com a população idosa, através de animação musical.
Para a realização dos "bailaricos” foram mobilizados esforços com vista ao trabalho em rede, estreitando-se laços com as IPSS/Associações cuidadoras, CSF e autarquia. Permitiu ainda divulgar as valências existentes nas diversas instituições, bem como, o trabalho realizado em cada uma.

Constribuir para o desenvolvimento local e investir na qualidade de vida das populações, nomeadamente, o bem-estar, a satisfação, a participação ativa e o contributo responsável na vida da comunidade, o combate ao isolamento e exclusão social, são algumas das preocupações dos CLDS+. Para o efeito, as equipas diligenciam esforços a fim de responder/solucionar/minimizar os mais dispares problemas sociais, contribuindo validamente para a construção de novos caminhos, auxiliando e promovendo o desenvolvimento pessoal e social.

\section{Referências}

Mortari, K. (2013). A compreensão do corpo na Dança, um olhar para a contemporaneadade, tese Doutoramento, Faculdade de Motricidade Humana, Universidade Técnica de Lisboa 